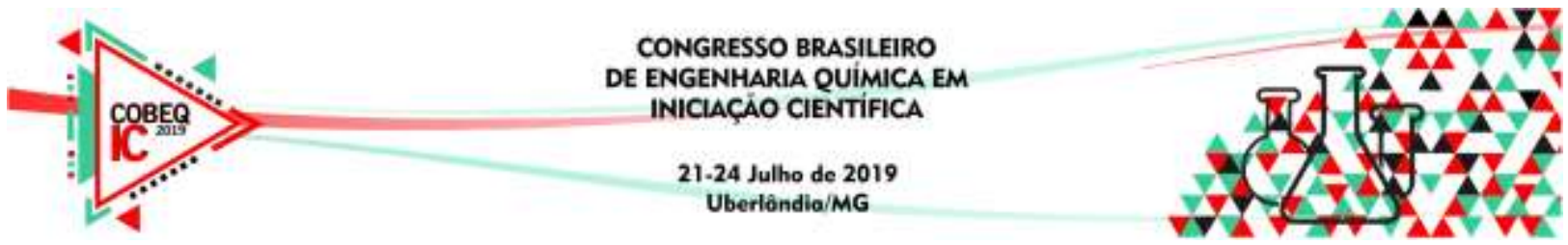

\title{
CARACTERIZAÇÃO FÍSICO-QUÍMICA DA AMÊNDOA E DO ÓLEO DE BARU SUBMETIDO À EXTRAÇÃO SÓLIDO- LÍQUIDO COM SOLVENTES ALTERNATIVOS
}

\author{
A. L. S. SOUZA1, J. S. MIRANDA ${ }^{1}$, R. C. S. SOUSA ${ }^{1}$, T. L. MENEZES ${ }^{1}$ \\ ${ }^{1}$ Universidade Federal de Viçosa, Departamento de Química \\ E-mail para contato: juliastockl@ outlook.com
}

\begin{abstract}
RESUMO - As fontes vegetais oleaginosas despertam grande interesse científico devido à possibilidade de enriquecer os alimentos e à aplicabilidade em cosméticos, combustíveis, entre outros. O óleo da amêndoa de baru apresenta grandes quantidades de proteínas, lipídeos de cadeia insaturada e elevado potencial antioxidante, com grandes concentrações de compostos fenólicos. Solventes como isopropanol e etanol vêm sendo investigados para substituir o hexano na extração de óleos, pois este é tóxico e proveniente de fonte não renovável. Assim, o presente estudo teve como objetivo estudar a variação dos efeitos de cada solvente na extração do óleo de baru, a fim de substituir o hexano. Os resultados mostraram que os óleos obtidos pelas extrações com isopropanol e etanol possuem semelhanças ao obtido através do hexano, sendo, portanto, viável a substituição deste nas indústrias.
\end{abstract}

\section{INTRODUÇÃO}

A amêndoa de baru (Dipteryx alata Vog.) se destaca por seu alto teor de proteínas, fibra insolúvel, potássio, magnésio e fósforo (Santos et al., 2015). Diante desta característica, a amêndoa de baru se mostra como uma promissora fonte alternativa de óleos vegetais, apresentando grande potencial quanto a sua utilização comercial. O óleo extraído vem sendo empregado como insumo de alto valor de mercado.

O teor de óleo na amêndoa de baru pode chegar a 40\%. Este óleo possui um alto grau de insaturação e sua fração lipídica tem em abundância os ácidos oleico (44,5\%) e linoleico (31,7\%), sendo este último mais alto que nos óleos de amendoim, de coco, de azeite de oliva e de dendê (Almeida, 1998; Vallilo et al., 1990; Togashi; Scarbieri, 1994).

O método de extração por solventes é comumente utilizado na extração de óleos vegetais a fim de se obter um maior rendimento em relação à prensagem, minimizar as perdas no processo, tornar o óleo adequado para o uso em alimentos e ser viável comercialmente. $\mathrm{O}$ hexano, um solvente orgânico, é o solvente mais utilizado como extrator por possuir alta estabilidade, ter uma estreita faixa de ebulição e resultar em um baixo teor residual nas tortas. Porém, alguns pontos negativos, como sua inflamabilidade, maior toxicidade e custo, justificam o estudo de alternativas ao seu uso (Moretto; Fett, 1998). 


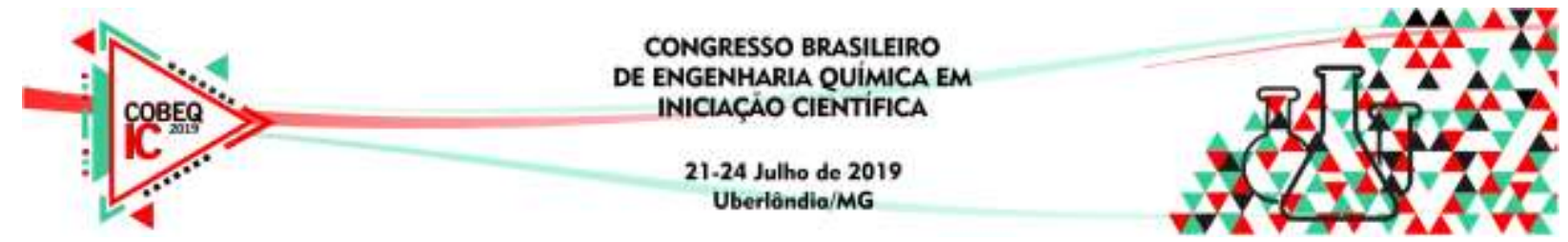

Como possíveis alternativas, podem-se utilizar determinados solventes como etanol, isopropanol, propanol e butanol, a fim de substituir o hexano nas indústrias alimentícias (Sawada et al., 2014). Entre as propostas tem-se o isopropanol, o qual é menos tóxico e menos inflamável e tem se mostrado eficiente na extração de óleo de soja, algodão e farelo de arroz, como apresentado por Harris e Hayward (1950), Baker e Sullivan (1983), Gandhi et al., (2003), Seth et al., (2010) e Capellini (2013). O etanol é obtido de fontes renováveis, sendo considerado economicamente viável e vantajoso, uma vez que é produzido em larga escala industrial no Brasil (Tomazin Junior, 2008).

Pelos aspectos acima relatados, o presente trabalho tem por objetivo estudar a extração do óleo da amêndoa de baru, pelo método de extração por solventes, investigando o uso de solventes alternativos ao hexano utilizando os solventes, etanol e isopropanol. A avaliação dos solventes será conduzida em equipamento soxhlet. Para a amêndoa de baru foi determinada a composição centesimal. Para o óleo extraído foram realizadas caracterizações físico-químicas, obtenção de índices analíticos, bem como a avaliação da sua atividade antioxidante.

\section{MATERIAL E MÉTODOS}

\subsection{Matéria-prima}

As amêndoas de baru utilizadas foram adquiridas no comércio da Cidade de Viçosa, MG. Os experimentos foram conduzidos na Universidade Federal de Viçosa (UFV), no Laboratório de Processos Biotecnológicos do Departamento de Química (DEQ), Laboratório Operações e Processos do Departamento de Ciência e Tecnologia de Alimentos (DTA).

\subsection{Processamento da Matéria-prima}

Para a análise da composição centesimal, as amêndoas de baru que estavam mantidas sob refrigeração, foram trituradas em moinho de facas tipo Willye Super, modelo STAR FT 80, tamizadas e classificadas quanto a sua granulometria, empregando peneiras com mesh entre 5 e 24. A granulometria utilizada foi uma mistura das frações retidas nas peneiras de 9 , 12 e 14 mesh.

\subsection{Extração do óleo de baru por Soxhlet}

A extração foi realizada em extrator tipo Soxhlet, com hexano (sistema de controle), etanol e isopropanol, como possíveis alternativas de substituição tendo como resposta o rendimento.

\subsection{Caracterização da amêndoa e do óleo de baru}

A composição centesimal da amêndoa foi realizada em triplicata com análises de proteína, carboidratos totais, cinzas, lipídios, teor de umidade e energia. Para caracterização dos óleos obtidos, foram realizadas as análises de acidez, densidade, índice de peróxido, índice de iodo, índice de refração, índice de saponificação e potencial antioxidante. 


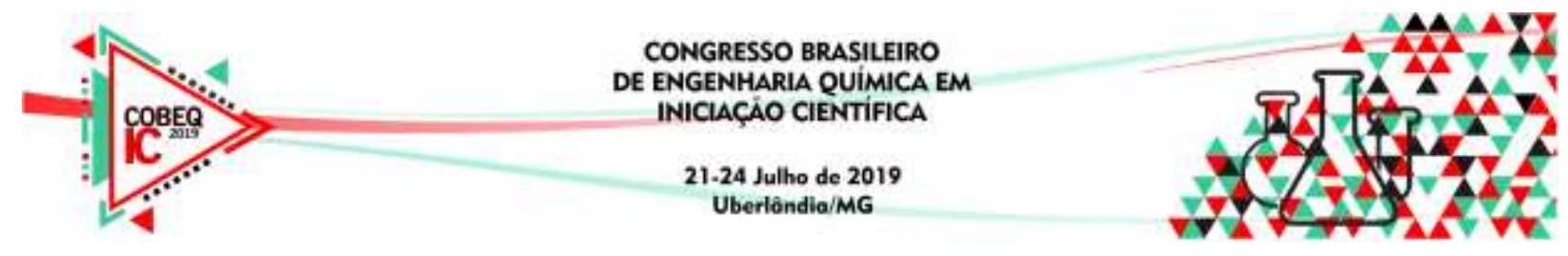

\subsubsection{Composição centesimal}

O teor de umidade foi obtido conforme técnica descrita pelo Instituto Adolfo Lutz (2008); o nitrogênio total foi determinado segundo o método de micro-kjeldahl e para conversão em proteína bruta utilizou-se o fator 6,25; lipídios totais foram extraídos por aparelho soxhlet com éter etílico e posteriormente determinados por gravimetria e resíduo mineral fixo obtido por incineração em mufla à $550^{\circ} \mathrm{C}$. Os carboidratos foram estimados por diferença. A partir dos dados obtidos, foi estimado o valor energético (calórico) das amostras considerando os fatores de conversão de Atwater de 4, 4 e 9 para proteína, carboidrato e lipídio, respectivamente, (Merril; Watt, 1973).

\subsubsection{Caracterização físico-química}

A acidez foi expressa em termos de ácidos graxos livres, podendo ser também em $\mathrm{mL}$ de solução normal por cento ou em g do componente ácido principal, geralmente o ácido oleico e seguiu o método descrito pelo Instituto Adolfo Lutz, 2008. A análise de densidade seguiu o método recomendado pela American Oil Chemists' Society (AOCS). O índice de peróxido determina todas as substâncias, em termos de miliequivalentes de peróxido por 1000 $\mathrm{g}$ de amostra, que oxidam o iodeto de potássio nas condições do teste, e foi obtido seguindo método descrito pelo Instituto Adolfo Lutz, 2008. O índice de iodo aplica-se à análise de triglicerídeos, de ácidos graxos livres e seus produtos hidrogenados e seguiu a prática recomendada pela American Oil Chemists' Society (AOCS). O índice de refração está relacionado com o grau de saturação das ligações e foi determinado em refratômetro Abbe conforme instruções do Instituto Adolfo Lutz, 2008. O índice de saponificação é a quantidade de álcali necessário para saponificar uma quantidade definida de amostra e foi quantificado segundo protocolo definido pela American Oil Chemists' Society (AOCS) (Instituto Adolfo Lutz, 2008). O potencial antioxidante em sequestrar radicais livres foi avaliado utilizando o método fotocolorimétrico que é baseado no sequestro do radical 1,1-difenil-2-picrilhidrazila (DPPH) pelos antioxidantes, com leitura em espectrofotômetro (Oliveira, 2015).

\section{RESULTADOS E DISCUSSÃO}

Para a composição centesimal, a amêndoa apresentou valores semelhantes à literatura em todos os testes, como mostrado na Tabela 1.

Os resultados da caracterização dos óleos extraídos com os solventes hexano, etanol e isopropanol estão explicitados na Tabela 2, que relaciona os valores obtidos com dados da literatura. O óleo apresenta elevados teores de proteínas e lipídeos. Lipídeos apresentam maior porcentagem de cadeias insaturadas, sendo representados pelos ácidos oleicos e linoleicos em sua maioria. Por isso, o óleo pode ser utilizado para enriquecer a alimentação humana e animal.

Além disso, o baru é um fruto com características semelhantes ao amendoim, por isso suas características foram comparadas. Segundo Lima (2012), os valores da caracterização dos óleos de baru e amendoim são semelhantes, portanto, satisfatórios. 


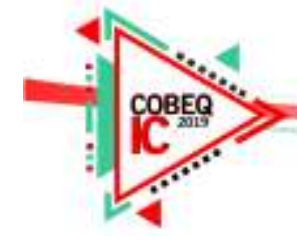

O teor de acidez e densidade obtidos para os óleos extraídos são satisfatórios e concordam com a literatura, indicando a possibilidade da utilização desses óleos em alimentos e na indústria em geral. Com relação aos índices de saponificação, refração e iodo os valores obtidos experimentalmente se assemelham ao que foi relatado por Lima (2012). O resultado dos índices de iodo e saponificação são qualitativamente semelhantes aos do óleo de amendoim, e indicam que os óleos caracterizados possuem maior composição de cadeias insaturadas, que contribuem para a redução dos riscos de obesidade e doenças cardiovasculares. Além disso, o óleo pode ser empregado como antirreumático (Ferreira, 1980; Barros, 1982) e apresenta propriedades sudoríferas, tônicas e reguladoras da menstruação, podendo ser utilizado também em tabacarias como aromatizante do fumo (Corrêa, 1931). Devido ao seu alto grau de insaturação, possui semelhança com o óleo de oliva e pode ser empregado como óleo de cozinha (Vallilo et al., 1990). Os valores obtidos no método de DPPH são semelhantes aos valores relatados por Borges (2013). Os resultados indicam que o óleo de baru possui um elevado potencial antioxidante. Esse potencial é extremamente importante em alimentos, pois é capaz de dificultar as reações em cadeia e danos causados por radicais livres, que atuam no organismo e que podem causar desde o envelhecimento até mutações e doenças como câncer.

Tabela 1 - Composição centesimal da amêndoa de baru

\begin{tabular}{|c|c|c|c|c|}
\hline \multicolumn{5}{|c|}{$\begin{array}{c}\text { INFORMAÇÃO NUTRICIONAL } \\
\text { Componente (g/100g) }\end{array}$} \\
\hline & $\begin{array}{c}\text { Amêndoa de } \\
\text { Baru }\end{array}$ & $\begin{array}{c}\text { LIMA, } \\
2012\end{array}$ & $\begin{array}{c}\text { BORGES, } \\
2013\end{array}$ & $\begin{array}{c}\text { Amendoim } \\
(\text { LIMA, 2012) }\end{array}$ \\
\hline $\begin{array}{c}\text { Valor energético } \\
\text { (Kcal/100g) }\end{array}$ & 559,12 & 549,43 & 570,17 & 595,42 \\
\hline Umidade & 5,68 & 6,18 & 3,67 & 6,47 \\
\hline Proteína & 25,92 & 23,66 & 24,82 & 32,93 \\
\hline Lipídios & 38,4 & 37,19 & 39,41 & 46,14 \\
\hline Carboidratos & 27,46 & 30,02 & 29,05 & 12,11 \\
\hline Cinzas & 2,54 & 2,77 & 3,05 & 2,35 \\
\hline
\end{tabular}

Tabela 2 - Caracterização do óleo da amêndoa de baru obtido por diferentes solventes e relacionados com dados referenciais do óleo de baru e amendoim

\begin{tabular}{|c|c|c|c|c|c|c|}
\hline \multicolumn{4}{|c|}{ Experimental } & \multicolumn{3}{c|}{ Referências } \\
\hline & Hexano & Etanol & Isopropanol & $\begin{array}{c}\text { LIMA, } \\
2012\end{array}$ & $\begin{array}{c}\text { BORGES, } \\
2013\end{array}$ & $\begin{array}{c}\text { Amendoim } \\
\text { (LIMA, 2012) }\end{array}$ \\
\hline Acidez (mg KOH/g) & 0,42 & 0,97 & 0,69 & 0,6 & 0,28 & 0,348 \\
\hline Densidade (g/mL) & 0,92 & 0,98 & 0,9 & 0,91 & - & 0,91 \\
\hline IS (mg KOH/g) & 191,5 & 198,4 & 250,3 & 190 & - & 195,49 \\
\hline II (mg I/100g) & 83,84 & 92,18 & 88,9 & 90,44 & - & 95,58 \\
\hline IP (meq/Kg) & 0 & 0 & 0 & 2,43 & 2,45 & - \\
\hline IR & 1,467 & 1,390 & 1,441 & 1,463 & - & 1,463 \\
\hline DPPH (mg ext/mL) & 0,03 & 0,06 & 0,22 & - & 0,19 & - \\
\hline
\end{tabular}




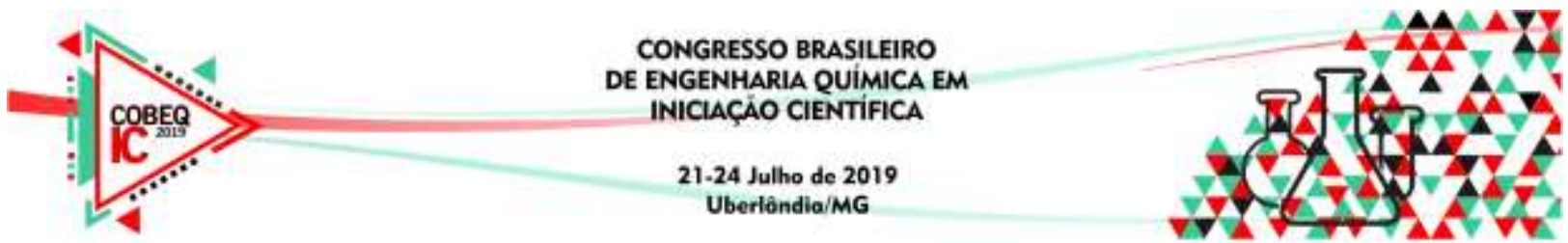

\section{CONCLUSÃO}

O óleo de baru apresenta características promissoras para a saúde, possuindo um alto potencial antioxidante, elevado teor de proteínas e lipídios de cadeia insaturada. O processo de extração é viável economicamente para a indústria, por ser um óleo que pode enriquecer alimentos de elevado valor agregado, além de poder ser empregado em indústrias de cosméticos e fármacos. Para substituição do solvente hexano, etanol e isopropanol são viáveis, pois se tratam de solventes não tóxicos e derivados de fontes renováveis, extraindo óleos com características semelhantes ao óleo obtido pelo hexano.

\section{REFERÊNCIAS}

ALMEIDA, S. P. Frutas nativas do Cerrado: caracterização físico-química e fonte potencial de nutrientes. In: SANO, S. M.; ALMEIDA, S. P. (Eds.). Cerrado: ambiente e flora. Planaltina: Embrapa-CPAC, 1998. p. 247-285.

BAKER, E. C. \& Sullivan, D. A. Development of a pilot-plant process for the extraction of soy flakes wih aqueous isopropyl-alcohol. Journal of the American Oil Chemists Society, 60(7), 1271-1277, 1983.

BARROS, M. A. G. Flora medicinal do Distrito Federal. Brasil Florestal, Brasília, DF, v. 12, n. 50, p. 35-45, 1982.

BORGES, T. H. P. Estudo da caracterização e propriedades das amêndoas do baru e óleo de baru bruto submetido ao aquecimento. 2013. Dissertação (Mestrado em Ciência e Tecnologia de Alimentos) - UFG, Goiânia, 2013.

CAPELLINI, M.C. Extração de óleo de farelo de arroz utilizando solvente alcoólico: avaliação de alteração na fração proteica e na composição do óleo. 2013. Dissertação (Mestrado em Ciências da Engenharia de Alimentos) - Faculdade de Zootecnia e Engenharia de Alimentos. USP, Pirassununga, 2013.

CORREAA, M. P. Dicionário das plantas úteis do Brasil e das exóticas cultivadas. Ministério da Agricultura, Rio de Janeiro, vol. II, pág. 476-477, 1931.

FERREIRA, M. B. Plantas portadoras de substâncias medicamentosas, de uso popular, nos cerrados de Minas Gerais. Informe Agropecuário, Belo Horizonte, v. 6, n. 61, p. 19-23, 1980.

GANDHI, A. P.; JOSHI, K. C.; KRISHNA, J.; PARIBAR, D. C.; SRIVASTAV, P. R.; KAWALKAR, J.; JAIN, S. K.; TRIPATHI, R. N.; Int. J. Food Sci. Technol. 38, 369, 2003. 


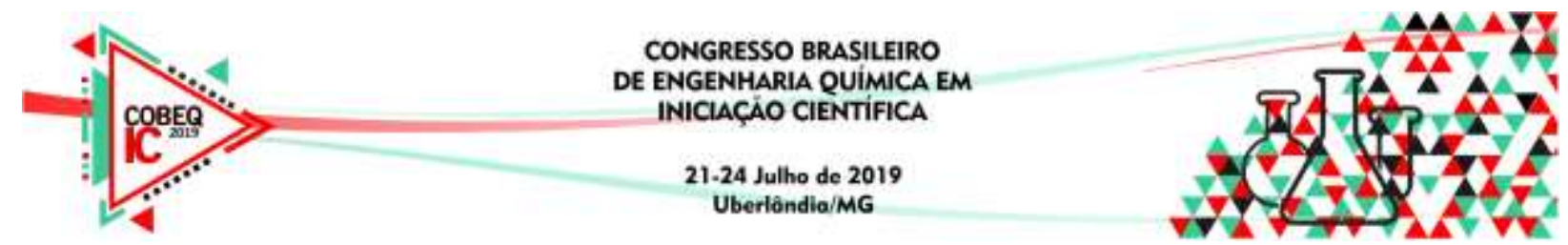

HARRIS, W. D., \& HAYWARD, J. W. Isopropanol as solvent for extraction of cottonseed oil. III. The use of recycling to effect solvent economy. Journal of the American Oil Chemists' Society, 27, 273-275. 1950.

INSTITUTO ADOLFO LUTZ. Métodos físico-químicos para análise de alimentos. Coordenadores Odair Zenebon, Neus Sadocco Pascuet e Paulo Tiglea. 4. ed. São Paulo: Instituto Adolfo Lutz, 2008. 1020 p.

LIMA, Jean Carlos Rodrigues. Efeitos dos Parâmetros da Extração e Avaliação da Qualidade Física e Química dos óleos de Baru e Amendoim. 2012. Disponível em: <file:///C:/Users/tiell/Desktop/Baru/Dissertacao_Jean\%20oleo\%20de\%20baru\%20e\%20amen doim.pdf>. Acesso em: 16 nov. 2018.

MERRIL, A. L.; WATT, B. K. Energy value of foods: basis and derivation. Washington: United States Departament of Agriculture, 1973. 105p.

MORETTO, E.; FETT, R. Tecnologia de óleos e gorduras vegetais na indústria de alimentos. São Paulo: Varela, 150p, 1998.

OLIVEIRA, A. C. D'. Desenvolvimento de bebida aromatizada da amêndoa de baru (Dipteryx alata Vog.). Dissertação (Mestrado em Saúde e Desenvolvimento na Região Centro-Oeste) - Universidade Federal de Mato Grosso do Sul, 2015.

SANTOS, S.B; MARTIS, M.A; CANESCHI, A.L; AGUILAR, P. R.M; COIMBRA, J.S.R. Kinetics and Thermodynamics of Oil Extraction from Jatropha curcas L. Using Ethanol as a Solvent. International Journal Of Chemical Engineering. Volume 2015. p. 1-9. 2015.

SAWADA, M.M., VENÂNCIO, L.L., TODA, T.A., RODRIGUES, C.E.C.. Effects of different alcoholic extraction conditions on soybeanoil yield, fatty acid composition and protein solubility ofdefatted meal. Food Res. Int. 62, 662-670. 2014.

SETH, S; AGRAWAL Y.C; GHOSH P.K; JAYAS D. S; SINGH, B.P.N. Effect of moisture content on the quality of soybean oil and extracted by isopropyl alcohol and hexane. Food Bioprocess Technology. V.3, n.3,p.121-127, 2010.

TOGASHI, M.; SGARBIERI, V. C. Caracterização química parcial do fruto do baru (Dipteryx alata Vog.). Ciência e Tecnologia de Alimentos, Campinas, v. 14, n. 1, p. 85-95, 1994.

TOMAZIN JUNIOR, Celso. Extração de óleo de soja com etanol e transesterificação etílica na miscela. 2008. Tese (Mestrado em Ciências) - Universidade de São Paulo, Piracicaba, SP, 2008.

VALLILO, M. I.; TAVARES, M.; AUED, S. Composição química da polpa e da semente do fruto do cumbaru (Dipteryx alata Vog.) - caracterização do óleo da semente. Rev. Inst. Flor., São Paulo, v. 2, n. 2, p. 115- 125, 1990. 